\title{
MAYORDOMÍAS Y FIESTAS PATRONALES EN LOS PUEBLOS ORIGINARIOS DE SANTA ANA TLACOTENCO Y SANTIAGO TZAPOTITLAN, NAHUAS DEL DISTRITO FEDERAL, MÉXICO
}

\author{
MAYORDOMÍAS AND TOWN FESTIVALS IN THE INDIGENOUS \\ COMMUNITIES OF SANTA ANA TLACOTENCO AND SANTIAGO TZAPOTITLAN, \\ NAHUAS OF MEXICO CITY, MEXICO
}

Mario Ortega Olivares* y Fabiola Mora Rosales ${ }^{* *}$

\begin{abstract}
Santa Ana Tlacotenco y Santiago Tzapotitlan son dos pueblos de origen nahua que están sometidos a la expansión de la mancha urbana de Ciudad de México, pero que reproducen sus usos y costumbres al celebrar fastuosas fiestas patronales. En ambos casos, el cargo de realizar los festejos lo cumple un complejo sistema de mayordomías. Por ello se sigue la discusión del sistema de cargos en la antropología en México. Tanto en uno como en otro pueblo las mayordomías entran en una competencia no disyuntiva por el prestigio de haber celebrado las mejores fiestas ante la comunidad. Le da continuidad, permite recrear y expande sus tradiciones y danzas.
\end{abstract}

Palabras claves: Mayordomías, sistema de cargos, Tlacotenco, Zapotitlán, prestigio.

Santa Ana Tlacotenco and Santiago Tzapotitlan are two Nahua indigenous communities that are subjected to the expansion of Mexico City's urban sprawl but that continue to preserve the tradition of celebrating magnificent town festivities in honor of their patron saints. In both cases, the responsibility for organizing the festivities is assigned and carried out through a complex system of festivity (cargo system) sponsors or stewards called "mayordomías" in Spanish. Hence, the discussion regarding town responsibilities continues in anthropology in Mexico. In both of these towns, the mayordomías enter into a non-conflictive competition in the community for the prestige of having celebrated the best festivities. The towns perpetuate this system, which recreates and expands their traditions and dances.

Key words: Mayordomías, cargo system, Tlacotenco, Zapotitlán, prestige.

\section{Tradiciones y fiestas}

Santa Ana Tlacotenco y Santiago Tzapotitlan son dos pueblos nahuas que ya se encontraban asentados en lo que hoy es la Ciudad de México antes de la conquista española en 1521, en ellos se celebran vistosas fiestas patronales a cargo de un sistema de cargos conocido como mayordomías. Este será el tema que se discutirá en este artículo.

Muchos de los rasgos de la cosmovisión mesoamericana que perviven en comunidades campesinas contemporáneas se reproducían alrededor del ciclo agrícola. En México, la expansión de las manchas urbanas y la caída del precio del maíz por la apertura de los mercados ha erosionado la producción campesina, sin embargo la identidad en esa superárea se sigue reproduciendo, pero ahora centrada en los festejos patronales. En los pueblos originarios vecinos a las metrópolis los ingresos urbanos y las remesas del extranjero sustentan festejos cada vez más vistosos, las fiestas en lugar de declinar como sería de esperarse por la creciente urbanización, se expanden en cantidad y calidad. El gran colorido, la música y las vestimentas rituales hacen de dichas fiestas un foco de identidad, en ellas se manifiesta la religiosidad popular como en las comunidades rurales.

Ciertos funcionalistas como Cancian suponían que las tradiciones mesoamericanas estaban destinadas a desaparecer ante los embates de la modernidad y el sistema político, sin embargo los pueblos han desarrollado una gama de estrategias de adaptación cultural a la competencia económica y degradación ambiental. En los pueblos originarios el sistema de cargos y las fiestas han tenido que recrearse para no sucumbir, mediante una reinvención de las tradiciones (Hosbawm y Ranger, 1983). A ello se debe que la religiosidad de los pueblos de la cuenca de

\footnotetext{
* Universidad Autónoma Metropolitana-Xochimilco, México. Correo Electrónico: ortegaoli@ hotmail.com

** Escuela Nacional de Antropología e Historia, México. Correo Electrónico: vocha1@ hotmail.com
} 
México aún muestre elementos mesoamericanos, tanto en los ritos como en la cosmovisión. Aunque no se puede ignorar cierto sincretismo con otras tradiciones como las africanas, o de las religiones evangélicas y protestantes. En nuestras tierras la "religión popular representa un proceso de bricolaje" (Rostas y Droogers, 1995: 82), en él conviven rituales mesoamericanas con simbolismos adoptados de diversas confesiones religiosas.

Andrés Medina identifica en la fiesta mexicana el foco de reproducción cultural de la cosmovisión mesoamericana:

\section{La fiesta mexicana solo es posible en la tradición rural por la existencia de una estructura organizativa que está en el meollo de la comunidad, el sistema de cargos, y en la que se articulan de manera compleja y original los procesos socioeconómicos, religiosos y étnicos que constituyen a la comunidad nacional, pero principalmente la india, de raíz mesoamericana (Medina, 1996: 7).}

Cuando comparamos la vida campesina con la vida urbana constatamos que así sucede. Es cierto que el estilo de vida cosmopolita inducido por la sociedad de mercado y sus medios de comunicación está transformando a las comunidades campesinas, pero muchas de ellas no abandonan su etnicidad comunitaria sino que la refuerzan al reajustarla. Sin embargo no podemos negar que la modernidad ya ha absorbido otros pueblos vecinos de las urbes mexicanas, desarticulando sus lazos comunitarios. En los pueblos originarios de la Ciudad de México quizás ya solo los abuelos recuerdan las raíces de sus tradiciones, pero no cabe duda que toda la comunidad las recrea al celebrarlas, incluyendo a algunos de los avecindados. En las fiestas comunales de estos pueblos originarios es:

[...] posible reconocer la riqueza de un simbolismo que nos remite a concepciones fundamentales del pensamiento mesoamericano [...] Como resultado de -un esfuerzo desplegado por la comunidad en un largo proceso de resistencia [...] frente a las presiones múltiples de una sociedad envolvente que se niega a reconocer la pluriculturalidad (Medina, 1996: 8).
Estamos de acuerdo con Medina cuando afirma que el sistema de cargos manifiesta la especificidad cultural e histórica del poder de una tradición que se arraiga en el pasado de Mesoamérica. Pero el poder estatal manifiesta un "abierto rechazo a los gobiernos tradicionales de las comunidades indias, y a sus dirigentes [...] por considerarlos un obstáculo para las finalidades de la política indigenista, orientadas a la integración nacional" (Medina, 1996: 12). De ahí la agresiva política estatal orientada a someter la organización política de las comunidades al derecho positivo propio del estado neoliberal, que mina poco a poco los usos y costumbres de las comunidades étnicas pese a su resistencia y esfuerzo de adaptación cultural.

\section{Los estudios sobre el Sistema de Cargos}

La estructura social de los grupos étnicos ha atraído la investigación antropológica durante décadas. Los investigadores se han enfocado al estudio de nuestras fiestas desde dos perspectivas diferentes. En una nos conducen desde la cosmovisión hacia temas relacionados con las creencias religiosas y con el mundo intangible. Tal como se expresan en las mayordomías encargadas de celebrar los festejos patronales. La otra analiza el funcionamiento de la estructura encargada de organizar las fiestas, lo que hoy conocemos como el sistema de cargos. Durante décadas un sector de los antropólogos en nuestro país se han concentrado en conocer a profundidad dichas formas de organización tradicional-que a semejanza de la ceremonia del potlatch- giran alrededor de la acumulación del prestigio, poder simbólico susceptible de trastocarse en poder político y económico.

\section{Sistema de Cargos y Mayordomías en la Antropología Mexicana}

El Sistema de Cargos, antes conocido como sistema de escalafón, ha sido un tema obligado cuando se discuten las mayordomías de las fiestas patronales. Tal concepto da cuenta de las múltiples actividades que un mayordomo desempeña para garantizar los festejos. Aunque las investigaciones de la antropología mexicana clásica han recurrido al concepto de mayordomía en prácticamente todos los contextos étnicos del país, todavía no hay un consenso acerca de su significado, pese a los avances en dicho sentido. 
Los pueblos originarios enmarcados por el Distrito Federal son un caso privilegiado para analizar cómo se interrelacionan sus autoridades locales con las formas de gobierno constitucional, cómo las oprime el Estado neoliberal y cuáles estrategias despliegan para ejercer una limitada autonomía al menos en materia de sus ciclos festivos anuales.

La investigación de Sol Tax en Chichicastenango en 1937 es considerada el momento fundante del estudio del sistema de cargos en el área mesoamericana. En ella el autor describió la existencia de una jerarquía de cargos seculares paralela a la de los religiosos. Tax descubre en ella la existencia de una carrera ascendente de cargos desde los más bajos a los superiores, hasta llegar al principal. Tax descubre que aunque tales cargos resultan de una elección, esta debe ocurrir siguiendo un determinado orden. Es así como identifica una carrera ascendente de cargos que va desde los más bajos hasta los más altos, hasta llegar al principal. Por ello, bajo el paradigma del sistema de cargos, la elección de los responsables ocurre siempre bajo la supervisión de los cargueros del más alto nivel. Tax reconoce, sin embargo, que en dichas jerarquías de cargos se pueden presentar "casi tantas variaciones [...] como municipios existen" (Tax, 1937: 110). Sin embargo, en los trabajos de Tax todavía no aparece la categoría de mayordomo como elemento central.

Alfonso Villa Rojas realizó años después otra investigación en los Altos de Chiapas, donde dio cuenta de una estructura de poder comunal sustentada en la cosmovisión mesoamericana y en las relaciones de parentesco. Su categoría central para analizarlo fue el nahualismo, según el cual ciertas personas cuentan con un álter ego o animal gemelo. El poder del nahual de los encargados corresponde al lugar que estos ocupan en la jerarquía local. El nahualismo expresa la idea de poder que tienen los indígenas de la localidad, lo que denota una relación entre la estructura política y la estructura religiosa, que hasta ese momento no se denominaba sistema de cargos. Aguirre Beltrán (1981) al profundizar en el tema de las autoridades tradicionales discutió la existencia de un gobierno de principales, concepto fundante que haría escuela en nuestro país. Según Aguirre, las poblaciones indígenas que habitan en el territorio mexicano comparten la existencia de una estructura de autoridad, que es al mismo tiempo política y religiosa, bajo el predominio de ancianos o principales.
Tanto Eric Wolf como Ricardo Pozas (1959) se interesaron en el sistema de cargos pero desde una perspectiva económica, al observar los grandes gastos erogados para sufragar los festejos patronales, a pesar del carácter precario de las economías campesinas y de sus profundas desigualdades. Ambos llegaron a la conclusión de que el sistema de cargos es una estrategia desplegada por las comunidades campesinas para impedir que una sola persona concentre grandes cantidades de dinero, pues ello introduciría una gran desigualdad. Es costumbre que las mayordomías o los cargos sean ejercidos casi siempre por personas casadas en su mayoría, por lo que será la pareja quien tendrá que absorber todos los gastos de la fiesta del santo patrono; la mayordomía funciona como un sistema nivelador de riqueza. Tanto Wolf (1967) como Nash (1966) describen cómo tal mecanismo impedía que un sector pequeño del pueblo acumulara dinero, pues los gastos en banquetes ceremoniales y festejos redistribuían la riqueza mediante el patrocinio de la fiesta. El beneficio de los festejos al redistribuir la riqueza era fomentar la simetría económica en las comunidades. Por ello solo aquellas personas que habían tenido algún éxito económico podrían asumir los cargos. Castaingts amplió tal perspectiva al discutir el papel de los sistemas de cargos al seno de las economías locales, pero bajo el contexto de la economía nacional. Cancian (1989) habría de criticar tiempo después tales argumentos por considerarlos economicistas, pues desde su punto de vista dicho mecanismo permite ostentar la riqueza y legitima las diferencias de clase al seno de las comunidades.

Consideremos ahora la relación entre el sistema de cargos y la cosmovisión mesoamericana: Calixta Guiteras (1972) en su clásico trabajo sobre la visión del mundo Tzotzil, comenta cómo la cosmovisión orienta la selección de las personas que se integrarán al sistema de cargos. Enfocada en la figura de la autoridad tradicional, Guiteras analiza cómo se viven los sistemas de poder comunales, así como la importancia del nahualismo en la comprensión de la categoría de persona propia de la cosmovisión. Su obra adquirió relevancia por haber influido en un generación nutrida de estudiantes de la Escuela Nacional de Antropología e Historia (ENAH).

La observación de la influencia de las autoridades tradicionales al interior de las comunidades condujo a la investigación del sentido político de los sistemas de cargos. Sieverts identificó al sistema de cargos entre los pueblos originarios como 
una forma de gobierno semiautónoma (Siverts, 1965). De ahí su interés por analizar la concepción étnica de la democracia. Por eso se enfocó en las amplias formas de participación de la comunidad en los festejos patronales y en su financiamiento, por medio de las cuales la comunidad influía sobre las autoridades y en la constitución de consensos.

Evon Z. Vogt, por su parte, observó el carácter normativo del sistema de cargos. Para el autor dicho sistema en tanto institución genera las normas que rigen el comportamiento de las personas en el momento de asumir algún cargo tradicional (Vogt, 1966). El sistema de cargos sería una estrategia orientada a evitar la concentración del poder y la autoridad mediante la rotación de los cargos, mecanismo que induce a la ampliación del número de participantes. Por esos años los sistemas de cargos eran objeto de estudio de las pesquisas a lo largo y ancho de nuestro territorio. Los mayordomos eran pensados como la conexión entre el mundo sagrado y el mundo terrenal de las comunidades. En estos sistemas de cargos los mayordomos asumían la obligación de suministrar todo lo requerido para realizar los festejos patronales.

Smith propuso el concepto de Sistema de Fiestas que, desde su punto de vista, se diferencia del sistema de cargos por no relacionarlas ni con la jerarquía política en la comunidad ni con la carrera ascendente para llegar a ser un principal (Smith, 1981). Su trabajo se centró en los nombres que se utilizan para denominar a los cargueros en distintas regiones de Mesoamérica, como pueden ser: mayordomos, patrocinadores, cofrades o fiesteros. Son estos personajes quienes se ocupan de organizar la celebración de la fiesta del santo patrono así como patrocinar la comida, la música, las procesiones, las danzas, los adornos y la cohetería, entre otros elementos festivos. Según Smith, ellos deben saber cómo se debe hacer una fiesta, para lo que deben poseer un gran nivel de conocimiento. Son los representantes de la comunidad frente al santo. Dicho autor distingue tres variantes que delinean las funciones de la jerarquía económica y de clase; la variante trunca que se ve acotada por el calendario festivo, la variante administrada donde un grupo específico la gestiona para obtener privilegios ante la iglesia, y la variante agregada donde se incrementa el número de encargados para reducir los costos económicos. Smith sienta las bases que años después retomaría Topete (1996) en sus investigaciones sobre el tema.
Fernando Cámara (1952) realizó un estudio analítico pionero acerca del funcionamiento del sistema de cargos. Marcó las diferencias entre lo religioso y lo político tanto en la etapa precolombina como en la que denomina europea y en la contemporánea. Su modelo de análisis se apoya en dos tipos de organización social: la centrípeta y la centrífuga. La centrípeta se caracteriza por promover la conservación del orden social, alrededor de un centro que es homogéneo, donde se privilegia el bien de la comunidad sobre el del individuo. La organización centrífuga, por lo contrario, es heterogénea, pues antepone al individuo sobre la comunidad, ya que no le interesa la conservación.

Fue Korsbaek quien sintetizó décadas de reflexión antropológica, al ofrecer el concepto de típico sistema de cargos, cuyas características serían las siguientes:

El sistema de cargos consiste en un (1)
número de oficios que están claramente
definidos como tales y que se (2) rotan
entre los miembros de la comunidad quie-
nes asumen un oficio por un (3) periodo
corto de tiempo después del cual se retira
a su vida normal por un largo periodo de
tiempo. Los oficios (4) están ordenados
jerárquicamente y el sistema de cargos
(5) comprende a todos -o casi todos- los
miembros de la comunidad. Los cargueros
(6) no reciben pago alguno durante su
periodo de (7) servicio, por el contrario,
muy a menudo el cargo significa un costo
considerable de tiempo en trabajo perdido
y en gastos en dinero efectivo, pero como
compensación el cargo (8) confiere al res-
ponsable un gran prestigio en la comunidad.
El sistema de cargos (9) comprende dos
jerarquías separadas, una política y una
religiosa, pero las dos jerarquías están
intimamente relacionadas, y después de
haber asumido los cargos más importantes
del sistema un miembro de la comunidad
es (10) considerado como "pasado" o
"principal" (Korsbaek, 1996: 82).

Debido a la importancia de su aportación, la antropología mexicana tendió a caer en el error de denominar sistema de cargos a cualquier forma de organización social en las comunidades. Korsbaek ha reconocido en estudios recientes que existen otras 
forma de organización en las comunidades donde no se presenta una carrera ascendente en los cargos. El sistema de cargos propiamente dicho sería una característica de algunas comunidades ubicadas básicamente en el sureste mexicano.

El papel de las relaciones de parentesco en los sistemas de cargos también ha sido una fuente de análisis. Falla reconoció el carácter fundamental del parentesco en el cumplimiento del compromiso de celebrar las fiestas adquirido por el familiar que recibió tal encargo; su punto de partida es la noción estructural del parentesco aportada por Lévi-Strauss (Falla, 1969). Si toda relación entre personas implica relaciones de poder, aun en campos tan pequeños como la familia nuclear, el recorrido en una carrera ascendente que avanza por dos estructuras paralelas remite al paradigma de la jerarquización de los cargos. Ulrich Kohler (1975) por su parte interpretó al sistema de cargos como si fuera un sistema de educación informal, aunque para los actores tenga otro sentido.

La línea del tiempo nos conduce a la obra de Saúl Millán, un pensador estructuralista contemporáneo, quien afirma que la organización del ciclo festivo y ceremonial entre los huaves de San Mateo del Mar, Oaxaca, tiene una función ordenadora. Considera al sistema de cargos como una expresión de la responsabilidad, la obligación y el control. Esto es lo que daría sentido a las diferentes formas de dominio en la vida social, que en otro sentido siempre están relacionadas con la cosmovisión del grupo social.

Topete (1996), al retomar la propuesta de Smith sobre el sistema de fiestas, considera que la estructura civil no necesariamente se encuentra ligada con la religiosa (Topete, 1996). Distingue una diferencia fundamental en ambas estructuras. En el caso de la religiosa los cargos son un servicio a la comunidad que se ofrenda de manera gratuita y hasta con una inversión económica por parte de los cargueros. El cargo es un servicio exclusivamente religioso que se puede tener durante un año o ser vitalicio, en el que la tarea es dedicarse de tiempo completo a organizar la fiesta. Se despliegan diversas actividades como solicitar cooperaciones, comprar comida, adornos, contratar a los músicos y sufragar la cohetería. La eficacia al desempeñar un cargo se puede valorar en términos de honor y capacidad de servicio, de acuerdo con el apego del festejo a la costumbre de los purépechas. Topete considera además de los cargos a aquellos puestos que forman parte de la estructura civil municipal y que pertenecen al ámbito político-administrativo, gozan de una remuneración económica y se relacionan con las labores comunitarias establecidas legalmente. Por otra parte considera al sistema de cargos tradicional como una forma de intercambio simbólico entre los santos patrones y los cargueros. Estos últimos además de recibir el reconocimiento por su labor comunitaria son premiados simbólicamente por el santo patrono con el don de la salud, el empleo o atendiendo alguna petición particular. El autor postula dos ideas, la primera reconoce que la vinculación entre la estructura religiosa y la civil puede ocurrir o no. También advierte que la jerarquización interior de dichas estructura puede darse o no.

Hemos seguido la discusión antropológica sobre el sistema de cargos. Incluyendo puntos de vista económicos, funcionalistas, estructuralistas, estructural-funcionalistas hasta aquello interesado en el orden simbólico de la cosmovisión.

\section{Las mayordomías en dos pueblos originarios amenazados por la mancha urbana}

$\mathrm{Al}$ sur-oriente de la cuenca de México se ubican dos delegaciones del Distrito Federal, donde persisten múltiples actividades campesinas y perviven ciertos rasgos de cultura nahua. Tanto la delegación Tláhuac como la de Milpa Alta poseen un abigarrado calendario festivo en el que se manifiestan ciertos rasgos de la cosmovisión mesoamericana. En ambas delegaciones reside tanto población de origen nahua como inmigrantes mestizos portadores de una cultura cosmopolita. Mientras que los migrantes tienden a ser propietarios privados, formales o informales de suelo urbano, los nahuas todavía poseen tierras ejidales donde cultivan maíz en la milpa. Los cambios generados por la expansión de la mancha urbana han implicado cambios en la estructura organizativa comunitaria de ambos pueblos.

Ahora se analizarán las mayordomías de Santa Ana Tlacotenco en Milpa Alta y las de Santiago Tzapotitlan en Tláhuac desde un enfoque comparativo. Ambos poblados comparten rasgos culturales que evocan tanto a los calpullis ${ }^{1}$ prehispánicos como a las instituciones españolas implantadas tras la conquista, pero como se han sincretizado tan íntimamente ya no es posible distinguir unos de otros. Por si fuera poco, sus tradiciones se han ido transformando para pervivir y enfrentar los acelerados cambios que experimentan, debido a la expansión de la mancha urbana de Ciudad de 
México, Carrasco (1975) ya ha dado cuenta de que los sistemas de cargos se transforman, debido al contacto de las comunidades con las metrópolis. Sin embargo, en estos pueblos se constata un intenso arraigo a tradiciones y costumbres, que los originarios reconocen fueron heredadas de sus anteriores, de sus antepasados. Desde tal contexto se intentará comparar a ambos pueblos.

\section{Santa Ana Tlacotenco, Milpa Alta}

En Santa Ana Tlacotenco la estructura cívica y la religiosa se encuentran legalmente separadas. La autoridad civil en el pueblo es el Coordinador Territorial, figura híbrida que ha sido elegida según los usos y costumbres del pueblo, pero al mismo tiempo es un empleado de la delegación ${ }^{2}$ encargado del enlace con la comunidad. La autoridad eclesial es ejercida por el párroco, aunque existe un Comité de Fiestas encargado de contratar a las bandas de música para la fiesta patronal y de solicitar una cooperación en el pueblo para sufragar su pago, además deben garantizar el pago de los castillos pirotécnicos. Cuando los cargos no son asumidos por alguien de propia voluntad, el mayordomo saliente escoge a quien lo sustituirá en el cargo. Aunque en Tlacotenco existen 31 mayordomías, no se presenta una jerarquización definida entre ellas. Además solo existen los cargos de mayordomo y recaudador. No existe una carrera ascendente para la toma de alguna de las mayordomías, aunque el cargo principal es el de mayordomo de la fiesta de Santa Ana, a quien se le considera el mayordomo grande. Los mayordomos asumen los gastos de la fiesta pero dicen que no lo consideran como una carga. Por otra parte, la cooperación que se recauda entre la comunidad para la compra de cohetería y el pago de la música disminuye los gastos del mayordomo. Esta mayordomía se considera la más grande debido a la importancia de la santa patrona en la comunidad, pero eso no demerita a las otras mayordomías.

El cargo de recaudador ${ }^{3}$ sigue en importancia al de mayordomo, aunque es respetado por ser el más antiguo. Los recaudadores deben recolectar dinero en la comunidad y de vez en cuando hacen las contrataciones de las bandas de viento. Además solicitan lonas a la Coordinación Territorial y con ellas instalan cobertizos en el atrio de la parroquia. Aunque el cargo de mayordomo se reservaba a los varones ahora pueden participar tanto las mujeres viudas como los jóvenes solteros, quienes asumen el cargo en compañía de un hermano u algún otro familiar como sus padres.

Los jóvenes originarios del pueblo pueden participar en las mayordomías para cumplir alguna manda por algún favor recibido de la santa patrona, o por el afán de preservar sus tradiciones. Si los mayordomos cumplen los compromisos de su cargo adquieren prestigio ante la comunidad, una especie de capital social. Doña Esther Gutiérrez comentó sobre el particular: -Sí hay más respeto, le han dicho a mi esposo, usted ha sido buena gente y también su esposa...

\section{La mayordomía de Santa Ana en Tlacotenco}

La señora Santa Ana es festejada el día 26 de julio de cada año. A Santa Ana, quien fue la madre de la Virgen María, se le atribuyen curas milagrosas en la comunidad, como el caso de una mujer que no podía tener familia y logró tener a sus hijos luego de solicitar el milagro. Dentro de las mayordomías que integran el complejo sistema de cargos de Tlacotenco destaca la de Santa Ana, responsable de la llamada fiesta grande. El requisito para que una pareja matrimonial se encargue de esta mayordomía es haberse casado por la Iglesia. Los mayordomos deben conjuntar un grupo de señoritas para que cambien las ropas de la Santa el día de la fiesta, tarea que se realiza a puerta cerrada con extrema discreción. Es muy importante que esas señoritas sean solteras, pues sería una falta de respeto que sirvieran a Santa Ana mujeres casadas aunque ya fueran ancianas. El cambio de ropajes es acompañado por el rezo de un rosario que puede ocurrir al final o durante la vestimenta de la Santa.

Los originarios de Santa Ana Tlacotenco también conocidos como tlacoteños no pueden ni atreverse a rechazar el cargo de una mayordomía, por temor a un castigo divino. Eso garantiza que se cumpla con el encargo después de haber sido registrado el compromiso. Se dice que quienes han rechazado un cargo para los festejos han sufrido enfermedades y hasta el robo de un automóvil.

\section{La participación}

Cuando un matrimonio asume el cargo de la mayordomía, las mujeres de la comunidad se apersonan en su casa y les ofrecen despensas, comidas o refrescos ${ }^{4}$. Los mayordomos reciben el apoyo 
de su familia nuclear y extensa, además reciben el apoyo de vecinos y amigos del pueblo para cumplir con las obligaciones inherentes al cargo. Como lo comentó el señor Magdaleno Chávez: "Hay mucha gente que ayuda y que no es de la familia, yo la verdad quedé muy asombrado [...] hay señoras que llegan con escobetas para lavar trastes [...] el día de mi compromiso alguien dijo: 'Mire, yo le traje maíz', otro dijo: 'Yo le traje un bulto de azúcar'”.

Además de la ayuda que llega de propia iniciativa, los mayordomos recorren el pueblo para invitar a los vecinos a la fiesta y solicitar una cooperación, costumbre que se está generalizando entre los pueblos originarios al sur del Distrito Federal. Un mayordomo nos comentó: "Tuvimos la delicadeza -el día 24- de invitar a todos los vecinos de la calle, de aquí para abajo y para arriba, y gracias a Dios todos vinieron y participaron para hacer las tortas... pero si no hubiera mano de obra o apoyo para realizar estos trabajos, pues cuándo".

En el cumplimiento de las obligaciones inherentes al cargo, los mayordomos también se apoyan en sus compadres, con quienes se estableció un parentesco ritual al llevar a los hijos a la pila bautismal o al altar (padrinos de velación): "Se cumple con la participación de las familias, los compadres son muy importantes, es un compromiso que implica gastar dinero".

\section{Las danzas}

Integrarse en las danzas tradicionales es otra forma de participar en las fiestas patronales de Santa Ana Tlacotenco. En el pueblo se celebran danzas como las de Santiagueros ${ }^{5}$, Pastoras, Vaqueros y la de Aztecas ${ }^{6}$. Aunque ya nadie recuerda con precisión su origen, don Aureliano dice que fueron retomadas hace unos 20 años $^{7}$. Con excepción de la danza de Pastoras, todas incluyen dos cuadrillas en la danza, lo que aporta un motivo de competencia entre mayordomos, pues se acostumbra elegir a la mejor cuadrilla para que vaya en primer lugar durante la procesión. En la danza de las Aztecas ${ }^{8}$ solo pueden participar mujeres, sus cantos incluyen estas alabanzas a Dios:

\section{Huaque tepehuaque nican cemanahuac Ahmo ti ixpolihuican Cenca huel hueyi cenca huel melahuac nictenamiqui monatzin Noique mocxitzin ${ }^{9}$}

Estas danzas las enseñan personas originarias del pueblo, interesadas en conservar la tradición y lo hacen por gusto como lo expresa el profesor Hipólito: "Hago lo que puedo y me falta por aprender, pero lo hago por la preservación de la danza que es esencial". Don Hipólito instruye a los interesados sobre la forma en que se debe bailar, toda vez que se considera importante que lo hagan "como debe de ser". Los danzantes dicen participar en estos grupos por el gusto de hacerlo y porque le tiene fe a Santa Ana, pero también manifiestan cierto temor al castigo celestial si rechazan la participación en las danzas que honran a la santa patrona. La mayordoma de la Danza de Vaqueros, durante 1985, comenta al respecto: "Cuando era joven yo iba a bailar de azteca y ya no quise. Me mordió una víbora. Iba a bailar con don Aniceto García. Me dijo: 'Vas a bailar, la vamos a poner atrás'. Y dije 'No'. Como ya no quise me fui al campo y ahí me mordió la víbora". Como un comentario aparte, diremos que también los mayordomos pueden ser castigados por negarse a atender a los peregrinos o a las personas que asisten a la fiesta patronal. Estos castigos se expresan por lo general como enfermedades leves o el robo de alguna propiedad.

Según sean sus cargos, los mayordomos se preparan con varios meses de antelación, van comprando poco a poco lo que se necesita para ofrecer el desayuno y la comida ceremonial. Para acceder a uno de estos cargos se debe ser originario del pueblo.

La fiesta de Santa Ana se ha transformado para tener continuidad temporal. En la actualidad se han incrementado los gastos económicos, la fiesta es más grande de lo que era antes. Ahora las opciones de entretenimiento se han diversificado, incluyendo juegos mecánicos, venta de ropa, alimentos, castillos y música de banda ${ }^{10}$. Según se recuerda, durante las procesiones los niños portaban canastas con poleo para regarlas por las calles. Los festejos en Santa Ana Tlacotenco incluyen un acto de agradecimiento, donde la comunidad acude a casa de los mayordomos, acompañados de un mariachi, para obsequiarles canastas con vino, fruta y cohetes ${ }^{11}$. Los festejos en Santa Ana Tlacotenco se celebran con apego a una estructura bien delimitada de responsabilidades que incluye a toda la comunidad. 


\section{Santiago Tzapotitlan, Tláhuac, Distrito Federal}

Por otra parte en Santiago Tzapotitlan existe una estructura de cargos correspondiente a la marcada competencia simbólica por el prestigio entre sus dos barrios. Cada uno tiene su propio santo patrono: un barrio está consagrado a la Señora Santa Ana y el otro al Señor Santiago, entre quienes se dice que existe un noviazgo. Aunque en el pasado podía diferenciarse un barrio de pobres y otro de ricos, la desigualdad económica rompió los límites territoriales tras la incorporación de la población originaria a empleos y servicios propios de la urbe.

En el pueblo se celebran dos Fiestas de Luces y Música durante el mismo año. El 4 de febrero la fiesta se dedica al Cristo de las Misericordias, asociada con el Año Nuevo Mesoamericano celebrado el dos de febrero, día de la Candelaria, con el encendido del Fuego Nuevo. La segunda celebración ocurre el 25 y 26 de julio en honor al Señor Santiago Apóstol y a la Señora Santa Ana, respectivamente. El crecimiento del pueblo originario hacia las dos nuevas colonias, La Conchita y La Nopalera, incrementó el número de participantes en los festejos, toda vez que los originarios de Tzapotitlan se han desplazado a ellas, extendiendo las redes sociales que se involucran en los cargos, aunque ahí conviven con población avecindada. Ahora el barrio, tras el quiebre de los límites territoriales, es más una unidad ritual que territorial. Por si fuera poco, las fronteras se han diluido entre el pueblo y la mancha urbana de la Ciudad de México. El arraigo al pueblo es tan fuerte que aún aquellos originarios que deben irse del pueblo, siguen regresando dos veces al año para participar en las celebraciones.

\section{El dualismo como forma de ser durante las fiestas}

La división espacial del pueblo en dos barrios constriñe estructuralmente a los originarios del pueblo, a una peculiar manera de ser en la celebración de las fiestas. Todo ha de ocurrir dos veces, una para el barrio de Santiago y otra para el barrio de Santa Ana. Este dualismo no se funda en el parentesco, pues ahora los originarios del pueblo son libres de casarse con quien lo deseen. Y antes debió haber sido muy difícil hasta un noviazgo, entre un muchacho y una muchacha originarios de diferentes barrios, porque en ambas mitades del pueblo se acostumbraba arrojar piedras a los jóvenes del otro barrio que se atrevían a entrar en su territorio.

Dado este modo de celebrar las fiestas, en el pueblo hay dos sistemas de mayordomías, uno para cada barrio. Por consiguiente hay dos templetes, dos programaciones de bandas, dos maestros de ceremonia. Durante la visita al Cristo de la Misericordia en el barrio de Los Reyes, la comida se sirve en dos tipos diferentes de platos, cuadrados desechables de unicel, cuadrados para un barrio y redondos para el otro. Hasta cuando se ha querido ir más allá del esquema binario, como en el caso de la comparsas, donde existe la comparsa de los ricos o Charros y la de los pobres o Zapatistas; el tercero en discordia es la comparsa de los Caporales, quien ocupa el sitio del término medio entre los dos opuestos polares. Entusiastas de los cargos y festejos, los originarios de Tzapotitlan gustan de crear nuevas comparsas, siguiendo tendencialmente un esquema de bipartición, si hay grupo de charros, fundan otro de charros niños; lo propio han hecho caporales y zapatistas, ahora hay caporalitos y niños zapatistas. Cuando ya existe comparsa de charros niños, el paso siguiente es constituir la de charros viejos o de la tercera edad. De la danza azteca del capitán Hermilo Jiménez proviene la danza de sus hijos. La danza de la Virgen de Guadalupe de su hermano Agustín dio origen a la Mesa de Concheros de su hija Charo.

Por supuesto que la lógica dominante en las relaciones sociales del pueblo es la del interés privado, pero no hay duda que algunos rasgos del dualismo mesoamericano perviven en la cosmovisión de los viejos campesinos y en el género de vida de los originarios del pueblo, en especial durante la celebración de las fiestas patronales. Muchos de los rasgos de dicha cosmovisión preservados en la memoria de los ancianos son desconocidos o ignorados por las siguientes generaciones, no tanto entre los adultos maduros como en los niños, quienes ahora reclaman ser originarios de Ciudad de México.

\section{El complejo sistema de mayordomías}

Las mayordomías que seguían un sencillo sistema de sitios, crecieron y se volvieron complejas para recrear sus tradiciones en medio de la acelerada urbanización. Ahora los originarios no solo se surten en almacenes como Walmart y suben al sistema de transporte colectivo Metro en la estación Zapotitlán, sino que su sistema de cargos y festejos 
sirve como mediador en su relación con el mundo citadino. A su vez, el Gobierno del Distrito Federal en Tláhuac participa de los usos y costumbres de las mayordomías, al asistir a la inauguración de la fiesta. Lo que debe ocurrir dos veces el mismo día en la plaza Juárez del pueblo, pues la ceremonia se repite en el templete del barrio de Santiago y en el de Santa Ana.

Ahora existe un complejo sistema de dos moitiés o mitades, con 23 mayordomías que se dividen entre los dos barrios, doce en Santiago y once en Santa Ana (Ortega, 1999). Cada una de estas mayordomías tiene entre sesenta y doscientos cincuenta integrantes y su número se incrementa. Cuentan con un presidente, un tesorero, un secretario y sus suplentes, encargados de recolectar puerta por puerta -entre vecinos y amigos- una cooperación, que ayuda a solventar los gastos de los espectaculares festejos. El patrocinio de las Fiestas de Luces y Música también proviene del derecho de piso que pagan los juegos mecánicos y puesteros durante la feria, así como los desembolsos personales de los integrantes de las mesas directivas y miembros de cada una de las dos mayordomías. El pueblo cuenta además con una Coordinadora General de Mayordomías, donde participan ambos barrios. En materia de prestigio es deseable pertenecer a una mayordomía, pero es mejor lograr ser el presidente de la mesa directiva y mucho mejor formar parte de la coordinadora de mayordomías. Sin embargo, también se valora tener un cargo en las comparsas, en las peregrinaciones o en la llamada "pastorela" de Semana Santa.

Aunque al interior de los barrios la toma de cargos se organiza por manzanas, estos se van rotando, sin embargo todos los jefes de familia deben apoyar a la mayordomía en turno. Su sistema de mayordomías es cíclico, pues cada barrio se va turnando para tomar el cargo de organizar la Fiesta de Luces y Música en progresión numérica. Siendo doce mayordomías en Santiago y dos las fiestas anuales, su ciclo es de seis años. El de Santa Ana dura cinco años y medio, por contar solo con once mayordomías para la dos fiestas anuales. Cada año los mayordomos deben sufragar los castillos pirotécnicos, las bandas de música, la comida, el enflorado de la parroquia, las misas, los mariachis, los sonideros ${ }^{12}$, así como lo trofeos para los eventos deportivos, entre otros gastos.

El cambio de mayordomía se realiza en el ritual de Chavarrio, en una misa que se celebra frente a un altar montado al aire libre. La plaza Juárez se divide en dos, un lado se asigna para las mayordomías del barrio de Santiago y el otro para las de Santa Ana. Los mayordomos salientes se sientan al frente del público en el altar y los nuevos atrás de ellos. Los mayordomos que cumplieron su responsabilidad pasan el cargo a sus relevos y tras entregarles una cera y una cruz vestida, intercambian sus lugares. Ese día, la mayordomía saliente entrega cuentas sobre su cargo ante la cruz y ante el pueblo. Al terminar, la música de banda toca por las calles en procesión e intenta opacar a las bandas representativas de las otras tres mayordomías, recordemos que hay dos mayordomías salientes y dos mayordomías entrantes. De igual manera se compite por lanzar la mayor cantidad de cohetes, durante las procesiones en el barrio de Santiago y en el de Santa Ana. Al término de la fiesta cada moitié realiza un paseo de toritos adornados con papel de china multicolor, que sus cohetes se queman en la plaza por la noche.

Según Wolf (1967: 179), el prestigio del mayordomo ante el pueblo aumenta al tener un cargo, por ello se esfuerzan en conseguir recursos y solventar los gastos. Siempre existen personas esperando poder tomar la mayordomía y gozar así del prestigio que los cargos otorgan a las personas originarias. El cargo más alto que se puede obtener es el de Presidente de la Mesa Directiva ${ }^{13}$, sin embargo, eso no significa el fin de la carrera de cargos tradicionales; se puede ser presidente y regresar a ser mayordomo y así sucesivamente. Incluso se puede tomar el cargo de tesorero y ser mayordomo después.

El cumplimiento de cargos y las cooperaciones para celebrar los festejos son requisito para poder ser sepultado en alguno de los dos panteones del pueblo, por lo que, al morir los familiares del difunto, deben presentar sus recibos de cooperación con la mayordomía de su barrio a fin de tramitar un espacio en el cementerio. Es posible que un presidente de mayordomía destacado llegue a ocupar un puesto en la Delegación Política del Gobierno del Distrito Federal, o que políticos del pueblo busquen ser mayordomos para ganar votos. Wolf comenta al respecto que cuando un hombre prestigiado cumple sus responsabilidades rituales, es considerado idóneo para asumir funciones públicas (Wolf, 1967: 195).

La figura del Coordinador Territorial de Santiago Tzapotitlan resulta paradójica, es al mismo tiempo la autoridad nombrada por el pueblo mediante sus usos y costumbres y un simple enlace oficial designado por el Delegado de Tláhuac ${ }^{14}$. El coordinador 


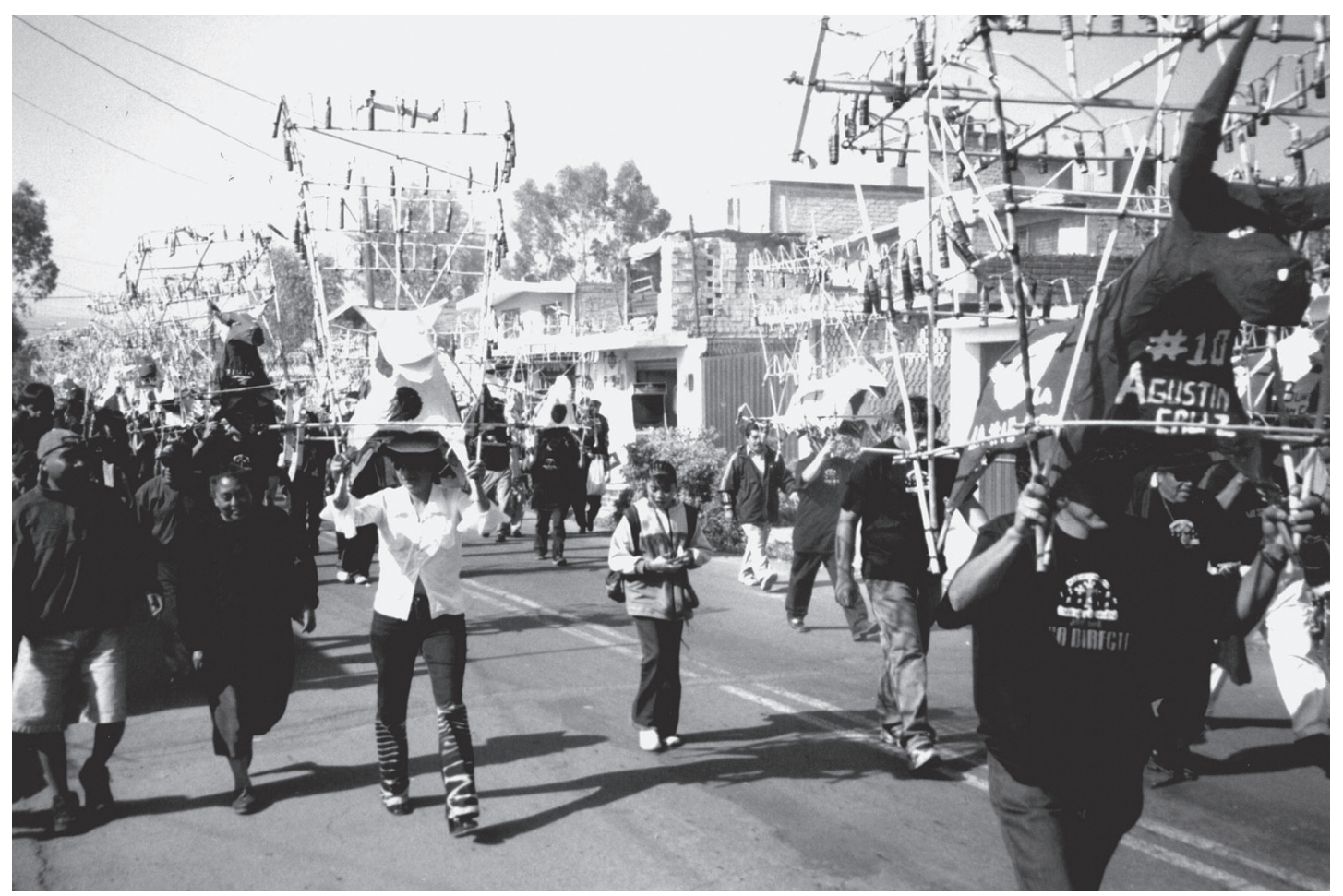

Desfile de "toritos" en Santiago Tzapotitlan a fines del siglo XX.

Mario Ortega Olivares.

lo mismo se coordina con la delegación para conseguir lonas y templetes durante las fiestas, que instrumenta los programas del gobierno capitalino dentro del pueblo, o es requerido para amonestar a un joven por golpear a su esposa frente a sus padres o padrinos. El pueblo solía elegir a su coordinador en asamblea pública por voto directo, pero ahora las autoridades de la ciudad organizan elecciones que fractura internamente al pueblo por el sistema de partidos. Afortunadamente las familias del pueblo están conscientes de que las relaciones de parentesco están por encima de las divisiones partidarias.

\section{Las danzas tradicionales}

Durante los Festejos de Luces y Música en Santiago Tzapotitlan se representan las danzas de Santiagueros y las de Aztecas. Entre los tres grupos de Danza Azteca integrados por parientes directos, hay una intensa rivalidad por el reconocimiento al seno del pueblo. También existen tres tipos de comparsas que danzan durante el carnaval: los Charros, los Caporales y los Zapatistas. Los Charros y los Zapatistas simbolizan de manera metafórica las diferencias de clase entre ricos y pobres, mientras que el medio pelo de los Caporales representa a la clase media.

Como las comparsas danzan en las mismas fechas, suelen surgir fricciones cuando se cruzan en el camino y se disputan el avance en primer lugar.

\section{A manera de conclusión}

Se han presentado dos sistemas de cargos en pueblos originarios ubicados al sur de la cuenca de México, ambos sometidos a las presiones de la expansión urbana y perdidos en el limbo jurídico de una legislación que al crear el Distrito Federal ignoró a las formas de gobierno nombradas por usos y costumbres. Las dos estructuras antes expuestas muestran la forma tangente de relacionarse con las autoridades civiles. Aunque la principal relación entre lo civil y lo ritual ocurre al solicitar infraestructura logística para las actividades de las mayordomías, en casos especiales -como alguna amenaza para toda la comunidad- pueden interactuar.

Aunque el poder constitucional y el derivado de los usos y costumbres convergen en la compleja 
figura del Coordinador Territorial, no existe otra vinculación directa entre el sistema de cargos tradicional y los cargos oficiales delegacionales ni en Tzapotitlan ni en Tlacotenco. En ambas estructuras se puede escalar y descender, pero también se puede transitar de una a otra sin seguir un orden. Esta figura jurídica no condiciona la toma de ningún cargo, ya sea oficial o tradicional.

Portal (1996: 35-38) distingue el sistema de cargos rural del sistema de cargos urbano, porque no existe una vinculación directa entre lo civil y lo político; asimismo, el número de mayordomías es más alto en el urbano que en el rural, además de otras características que se comentarán más adelante. En términos de jerarquización podemos decir que los cargos sí se valoran de manera ascendente. Ahora, aunque en Santa Ana los entrevistados dicen no aspirar a la presidencia del Comité de Fiestas o a ser recaudadores, se puede apreciar la alta concentración de prestigio que proporciona este tipo de cargos al interior de la comunidad. La jerarquización no es notoria en la vida cotidiana y el número de cargos que se pueden tomar simultáneamente por una persona, puede ser de dos o hasta más, porque existe una gran oferta de mayordomías en el pueblo. En Santa Ana no solo hay interés por el respeto que se adquiere al asumir un cargo en las mayordomías. La búsqueda de un cargo tradicional también se relaciona con expresiones de fe hacia la santa patrona y con señales recibidas durante los sueños, algo que no se manifestó de manera tan marcada durante las entrevistas en Tzapotitlan. En ambos casos la manera más eficaz de sumar y acumular prestigio entre el pueblo es realizar los festejos más espectaculares.

Aunque la competencia simbólica en Tzapotitlan es más aguda, también está presente en el sistema de cargos de Santa Ana, lo que se traduce en un esfuerzo constante por presentar mejores bandas, mejores castillos de luces y mejores danzas que las del mayordomo competidor. En Tzapotitlan tal rivalidad se manifiesta en dos niveles: a) en nivel micro, con la competencia entre el mayordomo anterior y el actual, y b) en un nivel mayor con la competencia ante el barrio dual, quien celebra el festejo en el mismo día y lugar.

En el presente artículo pudimos apreciar que la competencia fue una característica común entre ambos poblados. Y es muy probable que así ocurra en buena parte de los pueblos asentados en la cuenca de México. Como en ciertos momentos la competencia es tan aguda, parece que los mayordomos y sus familias se van a pelear con sus contrincantes, lo que en ocasiones sí llega a ocurrir. Sin embargo, no es la regla, pues la competencia tiene un carácter conjuntivo y no disyuntivo, pues la desaparición del contrincante implicaría la desaparición del juego. La competencia entre mayordomías tiene como consecuencia la superación de las fiestas. Y en el caso de Santa Ana Tlacotenco el perfeccionamiento de las danzas. La competencia da continuidad y facilita la reproducción de las tradiciones en ambos pueblos.

Entre los nahuas de Tzapotitlán existe una jerarquización más marcada, por ser más intensa la aspiración de alcanzar cargos superiores en los barrios y en el pueblo. En Santa Ana es más sincero el agradecimiento al mayordomo tras cumplir con su cargo y el respeto a su persona se eleva, se le tienen mayores consideraciones y su opinión es respetada en la comunidad.

\section{La condición de género en los sistemas de cargos}

Es de suma importancia resaltar que la participación de la mujer se manifiesta con más frecuencia en el sistema de cargos urbano que en el rural. Aun cuando en el típico sistema de cargos rural se reserva la participación en las mayordomías a los hombres, en los pueblos alterados por la mancha urbana las mujeres han traspasado los límites de la cocina ritual al desempeño de cargos de importancia superior. En Santa Ana tanto las mujeres solteras como las viudas pueden asumir cargos, aunque lo deben hacer en compañía de un familiar hombre que las apoye para organizar la fiesta. Las mujeres que habitan estos pueblos también tienen poder adquisitivo, pues se han integrado al mercado laboral citadino, ya sea como comerciantes o empleadas. El hombre ya no es el único que aporta económicamente a la familia, las mujeres también lo hacen y en muchos casos ellas son la cabeza de la familia. En Tzapotitlan se acostumbraba que los hombres se vistieran de mujer para bailar en las comparsas del carnaval, pues no les gustaba que las originarias anduvieran de locas. Hace unas tres décadas las muchachas de pueblo a quienes llevaban a bordo de carros, saltaron de manera intempestiva para bailar con sus parejas, desde entonces participan tanto mujeres como hombres en los bailes de cuadrillas. También han 
ganado el derecho a asumir ellas solas un cargo en las mayordomías, aunque como en el caso de los hombres cuentan con el apoyo de la familia extensa, amigos y vecinos. Una de ellas también ya ejerció el cargo de Coordinadora Territorial. Dicho cargo es un híbrido, el coordinador es al mismo tiempo el representante elegido por el pueblo según sus usos y costumbres, así como un empleado subordinado a las autoridades municipales de Ciudad de México. En ambos pueblos se constató que grupos de jóvenes se esfuerzan en defender y reproducir sus tradiciones a escala local. Es importante resaltar que bajo la tradición mesoamericana el acceso a los cargos estaba reservado a los adultos o ancianas; sin embargo, como lo señala Portal, ahora los jóvenes tienen acceso a los mismos (Portal, 1977: 58).

Los sistemas de cargos en la cuenca de México comparten dos características, por un lado la participación en las mayordomías son un medio para acceder a otro tipo de cargos más altos. Y por el otro la carrera escalafonaria es difusa (Medina, 2007: 78), pues se puede subir, bajar, dejar de participar y repetir en los cargos. De acuerdo con Portal, en estos pueblos originarios se lleva un registro minucioso de las personas que asumieron los cargos, por eso el uso de panteones -como es el caso de Tzapotitlan- está condicionado a la participación y colaboración de las personas con las mayordomías. Es así como en un esfuerzo por mantener sus tradiciones e integrarse a la modernidad, los nahuas de esta región de la cuenca de México han respondido a las formas de vida y las condiciones propias de la vida urbana. Los pueblos más que contraponerse a la urbanización, han creado una estrategia para aprovechar lo que la urbe les ofrece y reinventan sus tradiciones y costumbres para reproducirlas.

\section{Referencias Citadas}

Aguirre Beltrán

1981 Formas de gobierno indígena, México: Instituto Nacional Indigenista.

Cámara, Fernando

1952 "Religious and Political Organization", en Sol, Tax (editor), Heritage of Conquest, Glencoe: The Free Press, III, pp. 142-173

Cancian, Frank

1998 Economía y prestigio en una comunidad maya, Instituto Nacional Indigenista: México.

Carrasco, Pedro

1975 "La transformación de la cultura indígena durante la Colonia”, en Historia mexicana, vol. XXV, núm. 2 (98), octubre-diciembre, pp. 175-203.

Guiteras, Calixta

1972 Los peligros del alma: Visión del mundo de un Tzotzil, La Habana: Editorial de Ciencias Sociales, Instituto Cubano del Libro.

Hosbawm, Eric y Ranger

1983 The invention of tradition, Cambridge: Cambridge University Press.

Kölher, Ulrich

1975 Cambio cultural dirigido en los Altos de Chiapas, México: Instituto Nacional Indigenista, SEP-INI núm. 42.

Korsbaek, Leif

1996 Introducción al Sistema de Cargos, Toluca: Universidad Autónoma del Estado de México.

López Austin, Alfredo

1982 "La sexualidad entre los antiguos nahuas", en Familia y sexualidad en la Nueva España, Memoria del Primer Simposio de Historia de las Mentalidades, México: SEP, Fondo de Cultura Económica, SEP-80, núm. 41, pp. 141-176.

Medina, Andrés

1996 "Introducción”, en Introducción al sistema de Cargos, Korsbaek, Toluca: Universidad Autónoma del Estado de México.
Rostas y Drougers

1995 "El uso popular de la religión popular en América Latina: una introducción”, en Alteridades, año 5, núm, 9, pp. 81-91.

Nash, Manning

1966 Primitive and Peasant Economic Systems, Chandler: California.

Portal, María Ana

1996 Ciudadanos desde el pueblo. Identidad y práctica religiosa en San Andrés Totoltepec, Tlalpan, D.F., México: Dirección General de Culturas Populares-UAM Iztapalapa.

Pozas, Ricardo

1959 Chamula, un pueblo en los altos de Chiapas, México: Instituto Nacional Indigenista.

Siverts, Henning

1965 "The cacique of kancuk: a study of leadership in Highland Chiapas", en Estudios de Cultura Maya, vol. V.

Smith, Waldermar R.

1981 El sistema de fiestas y el cambio económico, México: Fondo de Cultura Económica.

Tax, Sol

1937 "Los municipios del Altiplano Mesooccidental de Guatemala", Traducción de L. Korsbaek, en Korsbaek, Leif (1996) Introducción al sistema de Cargos, Toluca: Universidad Autónoma del Estado de México, pp. 87-112.

Topete, Hilario

2005 "Cargos y otras yerbas", en Dimensión Antropológica, Año 12, Vol. 33, Escuela Nacional de Antropología e Historia-INAH, México, pp. 91-115.

Vogt, Evon Z.

1966 Los zinacantecos: un pueblo tzotzil de los Altos de Chiapas, México: Secretaría de Educación Pública-Instituto Nacional Indigenista.

Wolf, Eric

1967 Pueblos y culturas de Mesoamerica, México: Fondo de Cultura Económica. 


\section{Notas}

1 El calpulli antes de la conquista española era un grupo de familias cuyos miembros decían estar ligados por parentesco o amistad, y que reconocía la ascendencia mítica de un antepasado común. Los miembros del calpulli habitaban un territorio perteneciente al grupo ("barrio" le llamaron los españoles). Las autoridades internas del calpulli distribuían las parcelas Existía tendencia a la endogamia; los hombres del calpulli poseían profesiones comunes. Había en el grupo un alto grado de cooperación. Por último, pese a que los calpulli se agrupaban frecuentemente bajo un poder central, no perdían su individualidad y constituían una unidad política, administrativa, jurisdiccional, tributaria y militar (López Austin, 1982: 149).

2 La Ciudad de México está dividida en varias demarcaciones territoriales, en cada una existe una autoridad designada por el Gobierno de la Ciudad de México, al que se conoce como delegado al no ser elegido por la ciudadanía. A tales demarcaciones se les conoce como delegaciones.

3 Anteriormente, el cargo de recaudador implicaba recoger las cooperaciones, en la actualidad forma parte del Comité de Fiestas y sus funciones se han diversificado dependiendo de las necesidades.

4 Mayordoma de la Natividad de María, señora Marcela Pérez.

5 Se han ido integrando instrumentos nuevos como la flauta, el sonido y el tambor al estilo afro en esta danza.
6 Todas y cada una de las danzas mencionadas han sufrido cambios importantes en la vestimenta. Anteriormente se elaboraban a mano y ahora se compran hechos o se compran aplicaciones que se pegan en la ropa.

7 Entrevista con el señor Aureliano Pérez.

8 Originalmente en la danza estaba permitida la participación tanto de hombres como de mujeres.

9 Fuente: Profesor Hipólito Leyva originario de Santa Ana Tlacotenco.

10 Entrevista con el Señor Salvador Ávila.

11 Anteriormente, el regalo de agradecimiento era de una sola canasta, pero con el tiempo hay personas que obsequian hasta una treintena.

12 Especie de Disk Jockeys populares que animan los bailes en los barrios de Ciudad de México con música que tocan en grandes bocinas.

13 Según Medina (2007: 65), las Mesas Directivas son cambiadas cada seis años, y son los mayordomos los que se encargan de organizar el cambio de ellas; puede variar el número de integrantes pero siempre tiene un presidente, secretario y tesorero con sus suplentes.

14 Pues la desaparición del municipio libre en Ciudad de México para constituir el Distrito Federal en 1928, dejó en el limbo a sus pueblos originarios. 
